\title{
PROPAGANDAS INSTITUCIONAIS TELEVISIVAS E RESISTÊNCIA ${ }^{1}$
}

\author{
Adriane Roso* \\ Rosinéia Luisa Gass ${ }^{\#}$ \\ Moisés Romanini"
}

\begin{abstract}
RESUMO. Esse é um estudo exploratório-qualitativo referente ao uso de propagandas institucionais televisivas e discursos na mídia de massa (formas simbólicas) mediadas por agentes do governo e por uma instituição privada em favor da privatização da Companhia Vale do Rio Doce. Apoiado pela Hermenêutica de Profundidade e nos Estudos Críticos do Discurso (ECD), o objetivo do estudo foi demonstrar como essas formas simbólicas podem servir para estabelecer e reforçar relações de dominação. Considerando-SE que as mídias de massa têm a responsabilidade legal de informar e educar todos os cidadãos e que as propagandas televisivas institucionais em foco somente estimulam e valorizam a política neoliberal pró-privatização, conclui-se que essas formas simbólicas podem estar reforçando as relações de dominação.
\end{abstract}

Palavras-chave: Psicologia; neoliberalismo; propagandas.

\section{TELEVISION PROPAGANDAS AND RESISTANCE}

\begin{abstract}
This is a qualitative exploratory study related to the use of television institutional advertisements and mass media discourses (symbolic forms) mediated by governmental agents and by a private institution in favor of Companhia Vale do Rio Doce privatization. Supported by the Depth Hermeneutics and Critical Discourses Studies, the aim of the study was to demonstrate how these symbolic forms may serve to establish and reinforce relations of domination. Considering the mass media has the legal responsibility to inform and educate critically the citizens and the television institutional advertisements in focus only stimulate and value the neoliberal politics pro-privatization, it was concluded that these symbolic forms may be reinforcing the relations of domination.
\end{abstract}

Key words: Social psychology; neoliberalism; advertisements.

\section{PROPAGANDAS DE TELEVISION Y RESISTENCIA}

RESUMEN. Este es un estudio exploratorio cualitativo relacionado con el uso de propagandas institucionales de televisión y discursos de medios de comunicación (formas simbólicas) mediado por agentes gubernamentales y por una institución privada a favor de la privatización de La Companhia Vale do Rio Doce. Apoyado por la Hermenéutica de Profundidad y pelo Estudios Críticos Del Discurso, el objetivo del estudio es demonstrar como estas formas simbólicas pueden servir para establecer y reforzar relaciones de la dominación. Considerándose que los medios de comunicación tienen la responsabilidad legal de informar y educar críticamente a los ciudadanos y que las propagandas institucionales de televisión en foco sólo estimulan y valoran la política neoliberal de la privatización, fue concluido que estas formas simbólicas pueden reforzar las relaciones de la dominación.

Palabras-clave: Psicología social; neoliberalismo; publicidad.

\footnotetext{
1 As ideias desse texto foram apresentadas, inicialmente, em material online no "Mutirão da Comunicação América Latina e Caribe" (2010). No presente artigo, reformulamos as ideias iniciais do referido texto e acrescentamos novos achados

Doutora em Psicologia pela Pontifícia Universidade Católica do Rio Grande do Sul, Brasil(2005). Professora Adjunta da Universidade Federal de Santa Maria , Brasil.

\# Graduanda em Psicologia pela Universidade Federal de Santa Maria, Brasil.

If Graduando em Psicologia pela Universidade Federal de Santa Maria, Brasil.
} 
Ao longo de décadas a televisão tem servido de cenário para discursos políticos, argumentos e lutas entre os mais variados atores sociais, especialmente para os discursos das “"elites simbólicas', tais como jornalistas, escritores, artistas, diretores, acadêmicos e outros grupos que exercem poder com base no 'capital simbólico", (Van Dijk, 2008, p.45). Esses discursos públicos midiatizados podem, segundo Van Dijk (2008), influenciar as mentes dos cidadãos e exercer um papel na reprodução da estrutura social ${ }^{2}$, além informar incorretamente ou manipular.

No Brasil, a partir de 1995, o governo Fernando Henrique Cardoso iniciou uma nova fase de privatizações, em que os serviços públicos começaram a ser transferidos ao setor privado. Paralelamente a isso, surgiram os empreendimentos de atores políticos na tentativa de formar uma atmosfera favorável às privatizações das estatais.

Desde que a possibilidade de privatização de empresas se tornou pública, políticos, a sociedade civil e a população em geral têm se manifestado em relação a essas iniciativas, mostrando-se ora favoráveis, ora contrários, ora indecisos, gerando um confronto discursivo. Segundo Martins (1998), algumas pessoas defendem as privatizações por acharem que o Estado poderá dedicar-se mais à sua vocação, que é administrar justiça, ofertar segurança pública, educação, saúde, previdência e assistência social, ao invés de gerir empresas. Outros consideram que o Estado deve administrar essas empresas, as quais são geradoras de emprego em massa, fortalecendo seu papel perante a sociedade, ou seja, perante a vida social da população.

Um desses processos de privatização foi relativo à Companhia Vale do Rio Doce, que foi um dos eventos mais midiatizados na época, através de propagandas televisivas que veicularam um discurso "próprivatizações", assinados pelo Governo Federal (Programa Nacional de Desestatização; Banco de Desenvolvimento Econômico e Social - BNDES e Brasil em Ação).

$\mathrm{O}$ fato de propagandas serem assinadas por instituições governamentais não garante que seu conteúdo e efeito sejam democráticos; muito pelo

\footnotetext{
2 Conforme o autor, o exercício do poder com base no "capital simbólico" concede às "elites simbólicas" relativa "liberdade para decidir sobre os gêneros de discurso dentro de seu domínio de poder e determinar tópicos, estilo, ou forma de apresentação de um discurso". Nesse sentido, o poder não aparece apenas "nos" ou "por meio dos" discursos, mas, também, como força societal "por detrás" dos discursos, o que confere ao poder simbólico desses grupos um caráter de poder ideológico (van Dijik, 2008, p. 45).
}

contrário, formas simbólicas ${ }^{3}$ são sempre constituídas sócio-historicamente e recheadas de ideologia ${ }^{4}$. Apesar do confronto discursivo, coincidentemente ou não, “o discurso 'vencedor' é o identificado com o discurso governamental, o qual propõe e efetiva a privatização, o que faz pressupor estratégias de condução do processo" (Adão, 2006, p.16)

Neste sentido, conhecer o que uma propaganda institucional significa é tão importante quanto compreender como elas significam dentro de determinado contexto social. Como salienta Matos (2006), a propaganda institucional dialoga com a realidade e com os cidadãos, exibindo e comunicando a marca de cada período governamental, imagens do papel do Estado, apreensões do panorama social e das mudanças sociais e planos de ação sobre o respectivo contexto histórico.

Nosso objetivo é interpretar o caráter ideológico das propagandas, desvelando possíveis modos e estratégias utilizados pela ideologia neoliberal para a reprodução das relações de dominação. Especificamente, interessa-nos explicitar os modos pelos quais formas simbólicas em prol da privatização, de caráter estatal, não informam os cidadãos sobre os fatos históricos e sobre seus direitos, portanto, não cumprem a sua finalidade pública legal.

Neste artigo, analisamos três formas simbólicas contextualizadas em distintos momentos históricos brasileiros: (a) uma propaganda pós-privatização ("Vale - Sim, é possível") e (b) duas propagandas préprivatização da Vale. A propaganda pós-privatização, criada pela agência África, disponível no site da Vale ${ }^{5}$, foi ao ar em maio de 2008. A ideia da propaganda

3 Por formas simbólicas entende-se o amplo espectro de ações e falas (linguísticas ou não linguísticas ou quase linguísticas), expressões faladas ou escritas, imagens e textos, que são produzidos por sujeitos e reconhecidos por eles como construtos significativos (Thompson, 1995). Assim, quase tudo que vemos, ouvimos ou percebemos, em fonte de comunicação, pode ser entendido como uma forma simbólica.

4 Ideologia é definida por Thompson (1995) como as "maneiras como o sentido (significado), mobilizado pelas formas simbólicas, serve para estabelecer e sustentar relações de dominação" (p.79), que são relações estabelecidas de poder sistematicamente assimétricas, isto é, quando grupos particulares de agentes possuem poder de uma maneira permanente, e em grau significativo, permanecendo inacessível a outros agentes, ou a grupo de agentes, independentemente da base sobre a qual tal exclusão é levada a efeito.

5 Atualmente a propaganda está disponível em http://www.vale.com/vale/cgi/cgilua.exe/sys/start.htm?infoi $\mathrm{d}=3069 \&$ sid $=681$. Recuperado em 25 de novembro de 2010 . 
nasce com a mudança do nome da companhia e de sua logomarca, em novembro de 2007, quando a Companhia Vale do Rio Doce passa a se chamar Vale. Já a transmissão das propagandas pré-privatização iniciou-se no mês que antecedeu ao leilão do ano de 1998. As propagandas pré-privatização foram veiculadas nos canais abertos de televisão diariamente, no horário nobre (entre 18 e 24 horas), durante aproximadamente um mês.

\section{MÉTODO}

Esse estudo tem caráter qualitativo, que, para Gaskell (2008), passa pela compreensão de que o mundo social não é um dado natural, estático, pelo contrário, é ativamente construído por pessoas na vida cotidiana. Sua finalidade é explorar o espectro de opiniões, as diferentes representações sobre determinada temática.

Três pressupostos epistemológicos e ontológicos fundamentam o delineamento qualitativo desse estudo. O primeiro é que o saber e a comunicação são direitos legais de todos os seres humanos e como tal não podem ser transformados em mercadoria; o segundo é que a mídia eletrônica, de acordo com a Constituição da República Federativa do Brasil (1988), é uma concessão temporária de serviço público outorgada pelo Poder Público, e delegação do Estado para atender as finalidades e os interesses públicos, por meio da exploração de tais serviços, e assim, além de informar, ela tem, como acentuam Guareschi e Biz (2005), a tarefa de educar criticamente os cidadãos; e o terceiro é que, em pesquisa qualitativa, os pesquisadores

São uma parte importante do processo de pesquisa, seja em termos de sua própria presença pessoal na condição de pesquisadores, seja em termos de suas experiências no campo com a capacidade de reflexão que trazem ao todo, como membros do campo que se está estudando. (Banks, 2009, p. 9)

Isto quer dizer que a neutralidade não é uma possibilidade para nós; muito pelo contrário, defendemos nossa posição política, embora isso não possa interferir no rigor científico da produção de ideias, posição que se refere a assumir a perspectiva dos grupos dominados. Aqueles que estudam criticamente os discursos midiáticos não podem ser "neutros", como salienta Van Dijk (2008, p.15), "mas se comprometem com um engajamento em favor dos grupos dominados na sociedade. Eles assumem uma posição e fazem isso de modo explícito."

Utilizamos o método de estudo de caso, que consiste na junção do maior número de informações detalhadas, por meio de diferentes técnicas de pesquisa, com o objetivo de apreender a totalidade de uma situação e descrever a complexidade de um caso concreto (Goldenberg, 1999). Esse método caracteriza-se pelo estudo profundo e exaustivo de um ou de poucos objetos, de maneira a permitir seu conhecimento amplo e detalhado (Gil, 1999).

Para interpretar o caráter ideológico das formas simbólicas, inicialmente, as propagandas foram gravadas uma propaganda pós-privatização ("Vale Sim, é possível") e duas propagandas pré-privatização da Vale. Depois elas foram descupadas, ou seja, recortamos as cenas segundo suas estruturas de significado e estratégias discursivas. Os recortes e os discursos e dados visuais em sua forma integral foram lidos diversas vezes com o intuito de encontrar sentidos que se ligassem a elementos ideológicos.

A interpretação e reinterpretação de todo o material pesquisado foram feitas com base na psicologia social crítica, tomando alguns elementos da proposta da Hermenêutica de Profundidade (HP) e dos Estudos Críticos do Discurso (ECD). Tanto a HP quanto os ECDs estão interessados no estudo de questões e problemas sociais, das relações de dominação e das estratégias discursivas e ideológicas (Van Dijk, 2008; Thompson, 1995).

Dividimos nossa análise em duas etapas concatenadas. Na primeira, realizamos uma análise sócio-histórica do movimento pré-privatização e desestatização, assinalando que, ao naturalizar o jogo da privatização da Vale, os vencedores são os operadores de dominação, nomeadamente próprivatização. Ainda, elaboramos a análise discursiva das propagandas pré-privatização, quando tentamos mostrar que as formas simbólicas, em seu conjunto, visam modelizar e assujeitar o espectador/leitor, favorecendo que ele se torne alienado e desarticulado. No segundo momento discutimos os movimentos de resistência e criação, quando apontamos diversas estratégias das mídias de massa que objetivaram enfraquecer e desmoralizar os movimentos de resistência.

\section{ANÁLISE SÓCIO-HISTÓRICA DO MOVIMENTO PRÉ-PRIVATIZAÇÃO E DESESTATIZAÇÃO}

A realização de análises críticas de formas simbólicas implica interpretar o discurso não apenas como um objeto verbal autônomo, mas também como 
uma interação situada dentro de circunstâncias históricas específicas, e envolve acordos institucionais particulares como práticas sociais ou como um tipo de comunicação numa situação social, cultural, histórica ou política (Van Dijk, 2008;Thompson, 1995); assim, para interpretarmos a ideologia subjacente às propagandas institucionais televisivas, precisamos contextualizar o processo de desestatização e privatização nos cenários da América Latina, e em especial, no Brasil.

No final da década de 80 os governos da América Latina, segundo Boecker (1995), desencadearam uma política de atração de investidores estrangeiros diretos para as companhias e indústrias privatizantes, consequência da tese de que "um Estado enxuto é um Estado mais justo" e de que "o gigantesco consumo dos recursos e energias do Estado no capitalismo estatal deixou sobrar pouquíssimos para a execução de programas sociais".

Comparado com o de países como o México e a Argentina, o programa de privatização no Brasil demorou a se completar. Somente em 1990, com a criação do Programa Nacional de Desestatização PND através da Lei 8.031/90, a privatização tornou-se parte integrante das reformas econômicas iniciadas pelo Governo Fernando Collor de Mello (FCM). No mesmo ano, o BNDES foi nomeado gestor do Fundo Nacional de Desestatização (FND), tornando-se responsável por executar as decisões do Conselho Nacional de Desenvolvimento (CND) - órgão decisório na estrutura do PND - e por supervisionar, acompanhar e coordenar os trabalhos dos consultores e auditores até as operações finais de venda. Desde a criação do PND, em 1991, foram privatizadas 68 empresas e participações acionárias estatais federais, a maioria na siderurgia, química e petroquímica, fertilizantes e energia elétrica. Além dessas, foram repassados à iniciativa privada, por concessão, 7 (sete) empresas (BNDES, 2009).

Um dos primeiros passos do Governo para angariar a opinião pública a favor da privatização foi naturalizar esse fenômeno, ou seja, ao invés de retratálo como uma criação histórica, insere-o como um acontecimento natural.

$\mathrm{Na}$ fala que segue, do Presidente FHC [Fernando Henrique Cardoso], essa estratégia fica visível:

(...) ele (o Presidente) fez referência ainda "à marcha da história", que faz com que, em determinados momentos, "as transformações se imponham. Demora um pouco mais, um pouco menos, há um entrave aqui, um entrave ali, mas ela se impõe". (Leal, 1997, p. B-4)
Esse tipo de discurso pode nos orientar na direção da acomodação: não adianta lutarmos contra a privatização, pois ela é ressituada dentro da lógica da globalização como um fenômeno mundial natural e impossível de evitar. $\mathrm{O}$ discurso do Presidente facilita a conformação da população à inexorabilidade da privatização.

Dentro do programa brasileiro de desestatização incluiu-se a Companhia do Vale do Rio Doce. A Vale foi fundada em 1942, pelo Decreto-Lei N. ${ }^{\circ} 4.352$, mediante um acordo entre o governo de Getúlio Vargas, o governo norte-americano e o governo britânico (Companhia Vale do Rio Doce, 1992) Acordo de Washington. A indústria bélica destes países, empenhada no confronto com as potências do Eixo, necessitava de fontes alternativas de minério para seu suprimento (Adão, 2006).

Em 1997 tornou-se uma empresa privada, atuando nos cinco continentes e contando com a força e o valor de mais de 100 mil empregados, entre próprios e terceirizados. À época da privatização a Vale possuía, além das reservas minerais (e.g., ferro, alumínio e madeira) e recursos/capital (e.g., ferrovias, florestas e portos), 23 milhões de hectares do subsolo brasileiro a serem explorados e pesquisados, por tempo ilimitado. A taxa média de crescimento da Vale era de $13,6 \%$ ao ano e sua receita bruta era de US\$ 5,5 bilhões/anuais (Benjamim \& Bueno, 1997).

Nesse cenário, a corretora que faria a modelagem da venda, Merrill Lynch, ganhou destaque. Coincidência ou não, ela era a mesma corretora do Anglo American Bank (o quarto maior banco dos Estados Unidos). A Merryll Linch foi a responsável por criar muitas das regras e estratégias implícitas e tácitas durante o processo. Ela fez um relatório sigiloso sobre a Vale, entregue ao BNDES em agosto de 1996, cujo preço foi de 150 mil reais (Benjamim \& Bueno, 1997). Com esse preço, as oportunidades de acesso a esta documentação são inexistentes à população em geral, assim o processo de privatização foge ao controle social. A montagem de consórcios é uma estratégia extremamente sagaz, pois serve eficientemente para desmontar ou dissipar o controle social. Quanto mais "gigantes" capitalistas compuserem os consórcios, mais difícil será articular a população para lutar por seus direitos.

Segundo Benjamim e Bueno (1997), o BNDES tratou a Vale como uma questão meramente financeira. $\mathrm{O}$ valor do negócio foi calculado a partir da renda monetária que ele propiciaria aos novos donos num horizonte de tempo considerado economicamente relevante (30 anos), aplicando-se uma taxa de 
desconto sobre as rendas futuras para trazê-las ao valor presente.

Das duas propostas de gestão da Vale apresentadas ao Governo, o Consórcio Brasil, liderado pela Companhia Siderúrgica Nacional (CSN) venceu o leilão e adquiriu $41,73 \%$ das ações ordinárias do Governo Federal por US\$ 3,338 bilhões. Assim a Vale é atualmente uma empresa privada, de capital aberto, com sede na cidade do Rio de Janeiro (Observatório Social, 2006).

A própria noção de leilão eclipsa o caráter ideológico do processo de desestatização. O leilão, regulamentado pelas leis 21.981 de 19/10/32 e 22.457 de 01/02/33 e 8.934/94, é uma ilusão de democratização através da estratégia da universalização - acordos institucionais, que servem aos interesses de alguns indivíduos são apresentados como se servissem ao interesse de todos (Thompson, 1995). Nele tenta-se passar uma ideia de processo justo, transparente e eficiente de transação de bens. Regido pela lei de oferta e procura, segundo a qual o preço é obtido pelo maior lance oferecido pelos interessados arrematantes, os bens estão disponíveis à visitação pública durante três dias imediatamente precedentes ao leilão e os interessados devem comparecer no horário e local marcados para fazer o lance no bem em foco. Quantos poderão participar efetivamente desse processo? Quantos têm capital para apostar no cassino global? Assim, os leilões são mais um artifício que ritualiza a globalização, dificultando o controle social.

Em 2005 a Vale se tornava a maior empresa da América Latina, com um patrimônio estimado em 40 bilhões de dólares (R\$ 75 bilhões). Essa quantia é 12 vezes maior do que o arrecadado pela venda em dólares e 23 vezes superior quando tomamos o valor da privatização em reais (Brasilino, 2007).

Os números pós-privatização refletem quanto a Nação perdeu com a venda. Em 2006 a compra da Inco pela Vale por US\$ 18 bilhões tornou-a a segunda maior mineradora do mundo, atrás apenas da australiana BHP Billiton (Gamez, 2006).

Desestatizar e privatizar é aparelhar o "cassino global", onde máquinas de concentração de riquezas (consórcios) ampliam a desigualdade social. No fim das contas, quem ganha nesse jogo são os operadores de dominação, isto é, os vencedores são os que detêm o capital.

Nas propagandas em favor da privatização da Vale, os produtores escolheram um ator que recentemente tinha sido protagonista da novela Rei do Gado (Rede Globo, 1996-7). Esse mesmo ator foi apresentador de um programa chamado "Você decide". Ambos os programas foram veiculados no horário nobre.

Na telenovela, o ator desempenhou o papel de um sujeito capitalista, latifundiário e poderoso, que adquiriu suas terras usurpando as terras de seus familiares. No transcorrer da trama, acontece a transformação da personalidade do personagem - de mau-caráter, larápio e sovina - passa a ser um personagem de bom coração, justo. Essa transformação gera um aspecto carismático, capaz de influenciar e fascinar a audiência.

Fundamentos carismáticos se fazem necessários para que se possa representar um discurso como legítimo, justo e digno de apoio (Thompson, 1995). Vestido de terno branco e gravata, demarcando bem sua posição social (classe economicamente favorecida) e o locus da fala (lugar de poder), ele faz o papel de um mediador carismático. $\mathrm{O}$ tom de apelo emocional (olhar de quem pede encarecidamente algo) possibilita que o telespectador se identifique com o ator (mesmo que não sejam da mesma classe social) e tenda a se posicionar ao lado dele. O opressor é também, como argumentou Cavalcante (2010), um sedutor.

Essa estratégia ideológica costuma ser eficiente, como pondera Pachi Filho (2008): para o discurso da privatização é ser eficiente é preciso haver essa identificação com o público. Na verdade, não se acaba com o monopólio público afirmando, simplesmente, que ele irá se tornar privado. Você diz apenas que ele irá se tornar público e mais eficiente, o que vai mudar o regime de posse.

As propagandas mostram duas questões: se vale a pena privatizar a Vale ou não. No rodapé da tela de uma das propagandas aparece um endereço para o qual o telespectador pode escrever para sanar suas dúvidas ou opinar sobre o tema. Algo semelhante acontecia no programa "Você decide", no qual o ator fazia o papel de mediador, ou seja, aquele que mostra para o público os dois lados de uma questão polêmica. O episódio da semana trata sempre de problemas sociais que mobilizam as pessoas e apresentam duas possibilidades de solução. Pelo telefone os telespectadores determinam a solução do problema. Esse tipo de programa causa no telespectador a sensação de que ele realmente tem o poder de decisão sobre o tema veiculado.

Outra estratégia utilizada nas propagandas é a da racionalização, na qual o produtor de uma forma simbólica constrói uma cadeia de raciocínio que procura defender - ou justificar - um conjunto de relações ou instituições sociais e assim persuadir uma audiência de que isso é digno de apoio (Thompson, 
1995), o que fica claro nas argumentações do ator: "Por acreditar na Vale, por querer que a Vale cresça, o Governo quer vender (acentua o tom da voz) a Vale. E porque o Governo sabe que mais forte e mais ágil a nova Vale será muito mais lucrativa para o Brasil..."

O uso do adjetivo "nova" pode servir para desviar o real sentido da privatização, que é transformar um bem público em bem privado. O significado de "nova' articula-se à escolha dos tempos verbais futuros "vai ser" e "será”. Se aqui não é possível construir um discurso calcado num passado de ineficiência para o setor público - já que uma parcela considerável da população tinha uma noção do valor da Vale -, ainda se justifica, como defende Pachi Filho (2008), deslocar para o futuro toda a expectativa de mudança e de benefício.

Para que a "nova" Vale seja lucrativa é necessário desvalorizar o "velho". O velho é definido como ineficiente e retrógrado: "Compras de equipamentos, contratar gente, decidir investimentos. Pra tudo ela tem que enfrentar as regras rígidas das estatais" (Em Off: A Vale privatizada vai ser muito mais forte e vai dar muito mais lucro para o Brasil). E hoje as empresas precisam de agilidade para sobreviver".

A valorização da tecnologia (compras de equipamentos), a contratação de gente (uso da sinédoque - A que "gente" ele se refere?) e os investimentos caracterizam o discurso do capitalismo neoliberal global. Igualmente, contratar não é posto aqui por acaso; serve para capturar a representação do senso comum de que empresas privadas geram demissões. Ao invés de discutir os benefícios de ambos os processos, reforçam-se apenas os benefícios da privatização. A positividade (flexibilização e agilidade) da globalização é acentuada pela "compleição" do ausente: rigidez e morosidade da estatização.

Como o Governo, historicamente, também faz parte do "velho" - como um ente desprovido de real preocupação com os direitos dos cidadãos, na propaganda também se aposta na construção de uma imagem positiva a seu respeito: “(...) esse papo de que o Governo não está ligando pro que a Vale representa... isso (pausa) não vale!" (Em Off do lado direito da tela: NÃO VALE. O Governo está querendo se desfazer de um patrimônio). "Ficou claro para você? [Proposta interativa, causando a sensação de que $\mathrm{o}$ ator realmente está conversando com o telespectador]. É só assim que o Governo sabe agir. Com seriedade e clareza. Total transparência. [Em Off: "NÃO VALE" (esquerda do telespectador) e "VALE" (direita do telespectador). Música instrumental. Som da batida do malhete].
O som do malhete serve para pedir ordem na sessão ou para dar o veredicto final de um julgamento. No Brasil ele nunca foi usado, ao contrário do que parte da população imagina; aqui se usa uma espécie de campainha. Representa a disciplina e a ordem que devem predominar no ambiente. A escolha de um significante não verbal (som do malhete),aliada ao significado do malhete (veredicto e decisão final), produz um signo: Governo como autoridade máxima. Nada mais a discutir sobre o caso. O Governo sabe o que faz e como faz!

Desse modo, as propagandas vão ajudando a definir certo tipo de subjetividade dominante (subjetividade individualista-liberal), à qual cada telespectador tende a se conformar. As propagandas se tornam "equipamentos coletivos" teleguiando e codificando "as condutas, os comportamentos, as atitudes, os sistemas de valor" (Guattari \& Rolnik, 2007, p.150). No fim das contas, essas propagandas tentam modelar uma subjetividade completamente alienada, tentam produzir brasileiros conformados com interesses dos operadores de dominação.

\section{MOVIMENTOS DE RESISTÊNCIA E CRIAÇÃO}

Os movimentos de contra (marcados pelos gêneros "cartas abertas", manifestos e produção de artigos) e a favor da privatização da Vale (marcados pelos gêneros Pronunciamentos, produção de artigos e debates na esfera parlamentar) levaram, como reflete Adão (2006), a um confronto discursivo de diferentes atores sociais, constituindo, desse modo, dois conjuntos de enunciados marcadamente antagônicos.

Embora os discursos públicos das elites simbólicas tenham muita força na construção das representações das pessoas e na formação/cristalização das estruturas sociais injustas, os grupos dominados e seus membros - avisa Van Dijik (2008) - raras vezes se mostram totalmente impotentes; eles nunca são receptores passivos, são capazes de se engajar em diversas formas de resistência (contrapoder), o que, por seu turno, pode tornar o poderoso menos poderoso.

Não sabemos ao certo qual a parcela da população que tinha conhecimento do valor patrimonial que a Vale representava para a Nação, nem temos pesquisas que avaliem o impacto dessas propagandas na população; mas sabemos que diferentes atores sociais e movimentos sociais se mobilizaram para impedir a passagem de uma empresa vital e lucrativa para o Brasil às mãos de grupos ou indivíduos cujo interesse maior seria o lucro. 
O que sabemos é que essa mobilização foi obscurecida e ocultada por muitos governantes, através de uma estratégia denominada por Thompson (1995) de dissimulação, significando que as relações de dominação podem ser estabelecidas pelo fato de serem ocultadas, negadas ou obscurecidas, ou por serem representadas de uma maneira que desvia nossa atenção,como podemos observar no recorte da reportagem que se refere à fala do Presidente FHC:

\begin{abstract}
O Presidente (...) referiu-se ontem à barulhenta e persistente oposição à privatização da Companhia Vale do Rio Doce como a "histeria do contra" produzida por setores que estão organicamente, ideologicamente ligados às ideias de que o bom é fazer barulho. Nós somos o país do carnaval, estamos habituados com barulho, até gostamos. Sabemos que não é por aí, temos que ter nosso esforço em outra direção, (...) (Leal, 1997, p. 4)
\end{abstract}

Dois termos aqui são especialmente perniciosos, pois estabelecem uma sinédoque - quando um termo que está no lugar de uma parte é usado para se referir ao todo, ou vice-versa, ocasionando uma dissimulação das relações sociais, através da confusão ou inversão das relações entre coletividade e as partes, entre grupos particulares e formações sociais mais amplas (Thompson, 1995). Ao qualificar os movimentos individuais e coletivos contra a privatização como uma "histeria do contra", o Presidente os desqualifica, já que a histeria é normalmente vista como um "chilique de mulher" e ser "do contra" é ser rebelde em essência, sem razão.

Com o segundo termo - setores - o Presidente confunde e dissimula mais ainda a quem essa palavra se refere. Que setores são esses? São aqueles associados a baderneiros, que só sabem fazer barulho, não chiam, não apitam - não têm poder, consequentemente não precisamos ouvi-los. Os movimentos de resistência da população são confundidos com movimentos de anarquia.

Poucas semanas antes de anunciado o leilão da Vale, a mídia volta sua atenção à população. $\mathrm{O}$ "barulho" foi associado aos denominados "nacionalistas": Nacionalistas reagem [título]. Às vésperas do leilão da Vale do Rio Doce, protestos tomam conta do país e obrigam o governo a negociar ("Nacionalistas", 1997).

O uso do termo "nacionalista" serve para enfraquecer os movimentos sociais. Sejam barulhentos ou nacionalistas, esses movimentos representam descontentamento e resistência. A palavra "véspera" indica que movimentos de resistência são novos, sem tradição histórica, portanto, pouco confiáveis; e a palavra "obrigar" carrega uma conotação autoritária, invertendo o sentido das ações dos atores envolvidos: o governo não é autoritário ao impor a desestatização; imperiosos são os nacionalistas!

De um modo geral, as manifestações populares contra a desestatização da Vale foram retratadas através da fragmentação, quando as relações de dominação também podem ser mantidas por meio da fragmentação daqueles indivíduos e grupos que representam um desafio real aos grupos dominantes. São usadas estratégias como a de diferenciação (ênfase que é dada às diferenças e divisões entre pessoas e grupos, apoiando as características que os desunem e os impedem de constituir um desafio efetivo às relações existentes) e expurgo do outro (construção de um inimigo) (Thompson, 1995).

$\mathrm{O}$ uso do termo nacionalista ocasiona uma dicotomização da Nação em dois grupos: os do bem (não nacionalistas, pró-privatização) e os do mal (nacionalista, antiprivacionista). Quando essa dicotomização é feita, não há espaço para questionamentos. Por que não retratar os movimentos de resistência como movimentos de patriotismo? Ser nacionalista, argumenta Kujawski (1997), é repelir com veemência a participação de ideias, da cultura, da tecnologia e do capital estrangeiro como lesivos ao interesse de nosso país e como dissolventes do caráter nacional. Ser patriota é não temer nada do que vem de fora, mas selecioná-lo, separando o joio do trigo, assimilá-lo e reproduzi-lo de forma nova, criadora e caracteristicamente nacional.

Felizmente forças de resistência e de criação continuaram a se propagar na nossa sociedade. Documentários foram produzidos por entidades, movimentos sociais e profissionais de vários estados do país, com o objetivo de mobilizar a sociedade para o plebiscito pela anulação do leilão da Vale (que aconteceu em todo Brasil entre $1^{\circ}$ e 7 de setembro de 2007). Outros movimentos foram traçados para divulgar e formar interessados em participar da campanha "A Vale é nossa".

Esses processos de resistência articulados nacionalmente mostram que o descontentamento da Nação, num passado não muito distante, reverbera até o presente: ainda não "engolimos" o engodo da privatização. Como salientou Tavares, em 1997,

De todos os argumentos esgrimidos pelo Governo para justificar a venda da Vale não existe um só que tenha um mínimo de consistência técnica, econômica ou social. Ou são manifestações abstratas de fundamentalismo ideológico, do tipo (...) "a presença do Estado em atividades empresariais é coisa do 
passado", (...); ou são falsificações primárias da realidade, como "abater o estoque da dívida pública", "diminuir o déficit fiscal", "liberar recursos e capacidade gerencial para a área social" (...). (Tavares, 1997)

A pergunta que surge é: por que criar uma imagem positiva da Vale na atual conjuntura? Em 2007, movimentos sociais, das pastorais, da Igreja, dos sindicatos, das associações de bairro e de outras entidades pró-reestatização se articularam de forma capilar, reverberando as ondas de resistência. Diversas ações foram feitas, como panfletagem, encontros/seminários acadêmicos e populares, trabalhos de conscientização nas comunidades de todo o Brasil, produção do vídeo "A Vale é nossa" e a organização de um plebiscito no qual foram feitas quatro perguntas, das quais a primeira era sobre se a Vale deveria continuar nas mãos do capital privado.

O plebiscito alcançou o total de 3,7 milhões de votos. Pelo menos 24.075 urnas foram organizadas em 3.157 cidades brasileiras. Dos participantes, 94,5\% disseram "não" a uma Vale nas mãos do capital privado (Carrano, 2007). Infelizmente, a divulgação do plebiscito não teve a mesma proporção e investimento que as campanhas em prol das privatizações.

Para contrapor-se a esses movimentos de resistência a Vale se utiliza da mídia televisiva, em horário nobre, para mostrar seu vínculo com o Brasil e mostrar sua responsabilidade social por meio de propagandas. Assim, se "não há mais necessidade de propagar a urgência das privatizações, pois elas são um dado real" (Matos, 2006, p.12) agora existe a necessidade de mostrar que valeu a pena a privatização.

Na propaganda "Vale - Sim, é possível" podemos observar a utilização de diversas estratégias que podem servir para continuar reforçando a preponderância da ideologia neoliberal. Nessa propaganda, temos uma "nova" Vale, a empresa que, agora privatizada, tudo pode.

A propaganda inicia com a filmagem do espaço sideral envolto por uma atmosfera escura, que rapidamente se aproxima da luz do sol, como se alguém estivesse viajando no espaço e se aproximasse da Terra; em seguida, um homem sorridente, tendo nos seus óculos refletida a imagem de um céu nublado que cede espaço ao sol. Podemos pensar que o Estado aqui é representado pelo céu nublado, que é ineficaz na administração de tal empresa. Ele cede espaço ao sol, à globalização e, consequentemente, à privatização, permitindo o desenvolvimento e a felicidade das pessoas (metáfora).
Essa metáfora oculta a intenção do ideário neoliberalista de desconstruir os fundamentos teóricos e práticos de políticas que têm como referência o Estado de Bem-Estar Social (Carvalho, 2009). Com o neoliberalismo, o Estado que se busca estruturar é uma espécie de "Estado-empresário" (Fiori, 1994): enxuto, eficaz, livre das amarras da prestação de serviços e do peso das burocracias. Esse "Estado-empresário", ao manifestar o objetivo de corrigir as "disfunções burocráticas" (o céu nublado), alia-se ao projeto neoliberalista cujas estratégias centrais são "a venda do patrimônio público e a concessão de serviços à iniciativa privada" (Carvalho, 2009, p. 24).

As imagens aparecem na tela com a mesma rapidez com que elas somem - resultado da eficiência do "Estado-empresário". O paradoxo "velocidade tranquilidade" não é apresentado em vão: mostra ao telespectador que a Vale, apesar das mudanças velozes e intensas impostas pela globalização, continua servindo aos brasileiros como uma empresa-modelo, um modelo no qual todos podem se identificar e confiar. Tal contexto evidencia o estímulo à capacidade empreendedora e à autonomia - mesmo que regulada - dos indivíduos e grupos, induzindo-os, ao mesmo tempo, a lidar por sua conta com os riscos que o ameaçam - a velocidade e rapidez das imagens (Carvalho, 2009).

Assim como na propaganda pré-privatização, nessa também se faz presente a estratégia de racionalização (Thompson, 1995), na qual uma cadeia de raciocínio procura defender um conjunto de relações ou instituições, tendo como objetivo persuadir uma audiência de que isso é digno de apoio. Durante a passagem das cenas aparecem perguntas, e as imagens que são veiculadas nesses momentos se apresentam como respostas a elas, o que nos parece ser um argumento muito convincente.

Ao mesmo tempo em que aparecem imagens da natureza e da torre de uma plataforma petrolífera, coloca-se em Off a pergunta "É possível transformar minérios em sonhos?". Logo após, aparece a imagem de uma criança segurando uma bandeira do Brasil, à frente de seu pai. Reforçar através de formas simbólicas o "esperar magicamente", através do sonho cotidiano de um Brasil melhor ou do Brasil como o país do futuro (por isso a criança segura a bandeira), subliminarmente, reforça-se a passividade diante dos fenômenos sociais e econômicos, que passam a ser vistos de forma tão natural quanto a privatização da Vale. Não seremos nós quem fará o Brasil de nossos sonhos, mas, sim, as crianças!

Outra estratégia ideológica utilizada na propaganda é a simbolização da unidade (Thompson, 
1995), que consiste em construir símbolos de unidade, de identidade e de identificação coletivas, independentemente das diferenças e divisões que possam separar as pessoas que constituem esse coletivo. A terceira questão "É possível transformar minérios em orgulho?" tem como pano de fundo as imagens de um trabalhador casado (aparece a aliança em seu dedo) apanhando um pedaço de minério do solo (orgulho pessoal e local), da Torre Eiffel (orgulho internacional) e do Cristo Redentor (orgulho nacional) e de uma igreja brasileira (orgulho regional), monumentos reconhecidos mundialmente, que aqui servem como significantes de orgulho para todas as pessoas. Assim como o Cristo Redentor é motivo de orgulho para todos, a Vale também deve ser motivo de orgulho para os brasileiros, pois, além de ser uma empresa brasileira, ela também atua em âmbito internacional, representado pela Torre Eiffel.

Após uma sequência de imagens que nos remetem à união (aliança-anel), educação (crianças em uma sala de aula), criatividade (orquestra sinfônica) e vida (bebê em uma incubadora sendo cuidado por um profissional da saúde), a pergunta final nos dirige ao questionamento "Podemos transformar tudo isso (união, educação, criatividade, vida) respeitando as culturas locais e, ainda, contribuir para o desenvolvimento do mundo em que vivemos?"... A resposta nos é dada: "Sim, é possível", pois mesmo sendo privatizada, ela traz benefícios em larga escala e continua sendo genuinamente brasileira.

Lembramos, não obstante, como afirma Carvalho (2009), que o ideário neoliberal, ao impor sua agenda de desestatização, desregulamentação e desuniversalização dos direitos sociais, ampliou a desigualdade e a exclusão social. Ao diminuir (ou não ampliar) a sua participação na provisão de bens e serviços à população (como é o caso da privatização da Vale), o Estado amplia a distância entre incluídos e excluídos, dificultando a implementação de práticas democráticas efetivas.

Assim, o "Estado-empresário" vem contribuindo com o que o capitalismo neoliberal vem produzindo: duas sociedades distantes, inconciliáveis e estranhas cuja integração se produz pela via fetichizada e ilusória da televisão, que assim se converte em um fator de poder excepcional em nossas sociedades, capaz de "inventar presidentes" e destruir lideranças que lhe são contrárias (Borón, 1995).

Enfim, a propaganda faz justamente um contraponto com os movimentos de resistência, pois passa a ideia de que ela pode ser privada e ao mesmo tempo brasileira. Com ela privatizada, o Brasil entra no mundo globalizado e [só] assim promove seu desenvolvimento. A privatização passa a ser vista como algo natural dentro do sistema capitalista e globalizado, e tudo o que se opõe ao que é natural (como é o caso da campanha "A Vale é nossa") é considerado estranho, inimigo, e deve ser expurgado.

\section{CONSIDERAÇÕES FINAIS}

Procuramos mostrar neste estudo exploratório os modos como o uso das formas simbólicas (propagandas e discursos midiatizados de agentes do governo) pode servir para estabelecer relações de dominação. Quando falamos em dominação nos referimos às maneiras como o governo e outros agentes públicos constroem significados que não visam estimular a reflexão crítica e o diálogo entre agentes públicos e entes privados.

Neste sentido, o uso de um ator carismático para propagar os ideais pró-privatização foi extremamente perspicaz. $\mathrm{O}$ ator construiu um discurso racional, com respostas prontas, de modo que o telespectador não tinha espaço para raciocinar. Além disso, as propagandas tentavam levar o telespectador a acreditar que a privatização, além de inevitável, só traria benefícios aos brasileiros.

Diversas estratégias ideológicas ficaram visíveis na nossa discussão (eufemização, sinédoque, reificação, universalização, etc.). Com tantas estratégias em ação, não é de surpreender que as formas simbólicas possam servir para sustentar relações de dominação. De um lado está o governo, representado pelo ator, com seu ar de detentor do saber, portador de carisma, um ser ágil, esperto e transparente; do outro está o telespectador, manipulado por técnicas bem-elaboradas. $\mathrm{O}$ telespectador é levado a acreditar que é melhor deixar o governo (o dominador) decidir o caminho da história da Nação, já que ele "é igualzinho a você" (o dominado), como diz uma das propagandas préprivatização.

Nesse sentido, Guareschi (2000) nos alerta para o fato de os meios de comunicação terem se constituído em um instrumento de poder nas sociedades modernas. A mídia é um instrumento de poder porque ela não é apenas um instrumento de registro, ela cria a realidade, descreve e prescreve o mundo social, controlando o fluxo de informações e a produção do "imaginário social".

A informação, então, é um novo modo de desenvolvimento responsável pela produtividade do sistema político-econômico. No caso das propagandas aqui analisadas, a informação serve 
para defender o processo de privatização, o qual é produzido pelo capitalismo e, ao mesmo tempo o (re)produz. Os meios de comunicação de massa, ao veicularem mensagens que reforçam as relações de dominação, não atendem aos direitos legais de toda a humanidade, consequentemente não estão cumprindo sua tarefa de informar e de educar criticamente os cidadãos, burlando a Constituição da República Federativa do Brasil (1988), artigo 21, XI, XII, "a".

No modo hegemônico de subjetivação proposto pelo neoliberalismo, no qual o "cidadão" produzido é, antes de tudo, um consumidor, a ideia de valor predominante é derivada de uma perspectiva econômica das relações sociais e, do mesmo modo, de um plano da produção capitalística de modos de percepção que produzem corpos e mundos marcados por interesses privatizantes. Neste sentido,

Produção econômica e produção desejantes constituem, nesse quadro, dobras de um mesmo processo de produção de subjetividade. No neoliberalismo isso se manifesta, entre outros, pelo individualismo exacerbado e pelo consumo compulsivo de mercadorias - "caminho" mais curto para se alcançar a utopia da felicidade. (Carvalho, 2009, pp.25-26)

Por sorte, a população "cala, mas não consente", como diz o ditado popular. As formas simbólicas nos seduzem, nos capturam e recapturam, mas linhas de fuga - como as do movimento "A Vale é Nossa" - são traçadas até mesmo na calada da noite. O que precisamos fazer é continuar questionando os discursos hegemônicos e semear comunicações dialógicas.

\section{REFERÊNCIAS}

Adão, S. M. (2006). Os discursos confrontados no processo de privatização: o caso Companhia Vale do Rio Doce. Tese de Doutorado não publicada, Programa de Pós-Graduação da Faculdade de filosofia, Letras e Ciências Humanas, Universidade de São Paulo, São Paulo.

Banks, M. (2009). Dados visuais para pesquisa qualitativa. Porto Alegre: Artmed.

Benjamim, C., \& Bueno, R. (1997). Companhia Vale do Rio Doce. Atenção 3(10), 25.

BNDES - Banco Nacional de Desenvolvimento (2009). Privatização - Introdução. Recuperado em 16 agosto, de 2009, de http://www.bndes.gov.br/SiteBNDES/bndes/bndes_pt/Institucion al/BNDES_Transparente/Privatizacao/index.html.

Boecker, P. H. (1995). Transformações na América Latina. Rio de Janeiro: Jorge Zahar.
Borón, A. (1995). A sociedade civil depois do dilúvio neoliberal. In E. Sader \& P. Gentili (Orgs.), Pós-neoliberalismo: as políticas sociais e o Estado democrático. Rio de Janeiro: Paz e Terra.

Brasilino, L. (2007). Venda da Vale: um golpe no Brasil. América Latina en Movimiento, 25 agosto, 2007. Recuperado em 20 abril, de 2009, de http://alainet.org/active/19267\&lang=es.

Carrano, P. (2007). Mais de três milhões de votos pela retomada da Vale. Jornal Brasil de Fato, 8 outubro, 2009. Recuperado em 8 maio, de 2009 de http://www.brasildefato.com.br/v01/agencia/especiais/especial.20 07-08-24.9265285827/mais-de-tres-milhoes-de-votos-pelaretomada-da-vale.

Carvalho, S. R. (2009). Relflexões sobre o tema da cidadania e a produção de subjetividade no SUS. In S. R. Carvalho, S. Ferigato \& M. E. Barros (Orgs.), Conexões: Saúde Coletiva e Políticas de Subjetividade. São Paulo: Ed. Hucitec.

Cavalcante, M. C. (2010, outubro). O Opressor é também um sedutor? Colóquio de Retórica, Pontifícia Universidade Católica de São Paulo, Departamento de Língua Portuguesa, São Paulo, 2, Recuperado em 26 novembro, 2010, de http://www.estudosretoricos.com/resumos.htm.

Companhia do Vale do Rio Doce, (1992). A mineração no Brasil e a Companhia Vale do Rio Doce. Rio de Janeiro: Companhia do Vale do Rio Doce.

Constituição da República Federativa do Brasil (1988). Brasilia, DF, Recuperado em 24 novembro, de 2010, de http://www.senado.gov.br/sf/legislacao/const/.

Fiori, J. L. (1994). A governabilidade democrática na nova ordem econômica (Série Estudos em Saúde Coletiva 120). Rio de Janeiro: IMS/UERJ.

Gamez, M. (2006). Mineração. A Vale ganha o mundo. Isto É, Economia \& Negócios, 1 novembro 2006. Recuperado em 10 maio, de 2009, de http://www.terra.com.br/istoe/1932/economia/ 1932_vale_ganha_o_mundo.html.

Gaskell, G. (2008). Entrevistas individuais e grupais. In M. W. Bauer \& G. Gaskell. Pesquisa qualitativa com texto, imagem e som: um manual prático. (P. A. Guareschi, trad., 7a ed. pp.64-89). Petrópolis, RJ: Vozes.

Gil, A. C. (1999). Métodos e técnicas de pesquisa social. São Paulo: Atlas.

Goldenberg, M. (1999). A arte de pesquisar: como fazer pesquisa qualitativa em Ciências Sociais (3a ed.). Rio de Janeiro: Record.

Guareschi, P. A. (Coord.). (2000). Os construtores da informação: meios de comunicação, ideologia e ética. Petrópolis, RJ: Vozes.

Guareschi, P. A., \& Biz, Osvaldo (Orgs.). (2005). Mídia \& Democracia. Porto Alegre: Evangraf.

Guattari, F., \& Rolnik, S. (2007). Micropolítica: cartografias do desejo. Petrópolis, RJ: Vozes.

Kujawski, G. de M. (1997). Patriotismo e nacionalismo. (Cadernos Liberais -3). São Paulo: Massao Ohno.

Leal, L. E. (1997, maio 2-4). Presidente Fernando Henrique critica a 'histeria do contra'. Gazeta Mercantil, p. B-4, 10c.

Martins, I. G. da S. (1998, dez). Privatizações. Revista Jurídica Consulex, 1, 35.

Matos, H. (2006). Persuasão e denúncia: a trajetória do debate da privatização no Brasil. Trabalho apresentado no GT Imagem Pública Política do I Congresso Anual da Associação Brasileira 
de Pesquisadores de Comunicação e Política. Salvador: Universidade Federal da Bahia.

Nacionalistas Reagem. IstoÉ, (1997)., 23 abr. [Capa].

Observatório Social, (2006). Companhia Vale do Rio Doce: perfil de empresa. São Paulo: Instituto Observatório Social.

Pachi Filho, F. F. (2008). Privatizar para tornar público: o discurso dos jornais brasileiros. Revista eletrônica do Instituto Humanitas Unisinos, 22 abril de 2008. Recuperado em 21 abril, de 2009, de http://www.observatoriodaimprensa.com.br/artigos.asp?cod=483J DB012.

Tavares, M. da C. (1997). A Importância da Vale do Rio Doce. Correio Brasiliense, 6 março de 1997. Recuperado em 16 agosto, de 2009, de http://www.eco.unicamp.br/artigos/tavares/ artigo24.htm.
Thompson, J. B. (1995). Ideologia e cultura moderna: teoria social crítica na era dos meios de comunicação de massa. Petrópolis, RJ: Vozes.

Van Dijk, T. A. (2008). Discurso e poder. São Paulo: Contexto.

Recebido em 11/09/2009

Aceito em 22/12/2010

Endereço para correspondência:

Adriane Roso. Universidade Federal de Santa Maria, Departamento de Psicologia, Prédio de Apoio, Sala 316. CEP 97015-372, Santa Maria-RS, Brasil.E-mail: ufsm@gmail.com. 